2014

\title{
Estimating Hydroxyl Radical Photochemical Formation Rates in Natural Waters During Long- Term Laboratory Irradiation Experiments
}

Luni Sun

Old Dominion University

Hongmei Chen

Old Dominion University

Hussain A. Abdulla

Old Dominion University

Kenneth Mopper

Old Dominion University, kmopper@odu.edu

Follow this and additional works at: https://digitalcommons.odu.edu/chemistry_fac_pubs

Part of the Biogeochemistry Commons, Chemistry Commons, and the Environmental Indicators and Impact Assessment Commons

\section{Repository Citation}

Sun, Luni; Chen, Hongmei; Abdulla, Hussain A.; and Mopper, Kenneth, "Estimating Hydroxyl Radical Photochemical Formation Rates in Natural Waters During Long-Term Laboratory Irradiation Experiments" (2014). Chemistry \& Biochemistry Faculty Publications. 149.

https://digitalcommons.odu.edu/chemistry_fac_pubs/149

\section{Original Publication Citation}

Sun, L. N., Chen, H. M., Abdulla, H. A., \& Mopper, K. (2014). Estimating hydroxyl radical photochemical formation rates in natural waters during long-term laboratory irradiation experiments. Environmental Science: Processes \& Impacts, 16(4), 757-763. doi:10.1039/ c3em00587a 


\section{Environmental Science Processes \& Impacts}

\section{Accepted Manuscript}

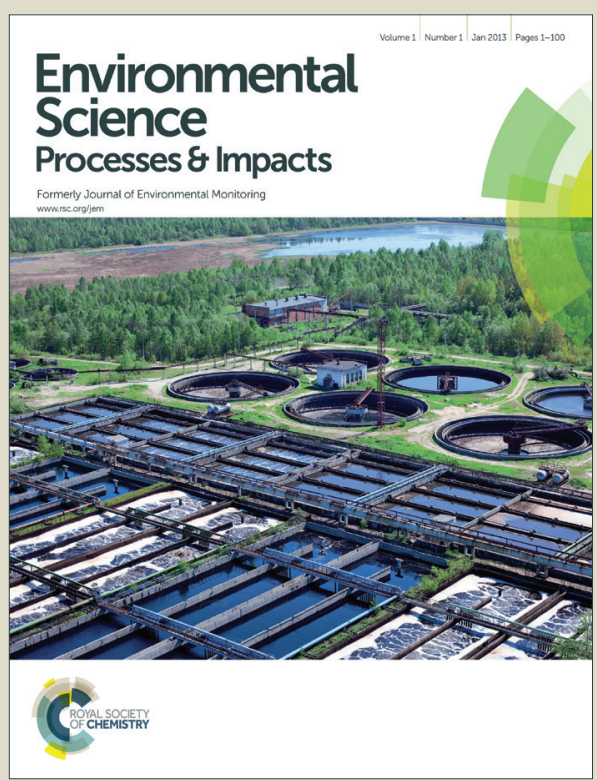

This is an Accepted Manuscript, which has been through the Royal Society of Chemistry peer review process and has been accepted for publication.

Accepted Manuscripts are published online shortly after acceptance, before technical editing, formatting and proof reading. Using this free service, authors can make their results available to the community, in citable form, before we publish the edited article. We will replace this Accepted Manuscript with the edited and formatted Advance Article as soon as it is available.

You can find more information about Accepted Manuscripts in the Information for Authors.

Please note that technical editing may introduce minor changes to the text and/or graphics, which may alter content. The journal's standard Terms \& Conditions and the Ethical guidelines still apply. In no event shall the Royal Society of Chemistry be held responsible for any errors or omissions in this Accepted Manuscript or any consequences arising from the use of any information it contains. 
Environmental Impact Statement for:

Manuscript ID EM-ART-11-2013-000587

Title: Estimating $\mathrm{OH}$ radical photochemical formation rates in natural waters during long-term laboratory irradiation experiments (Sun et al.)

The hydroxyl $(\cdot \mathrm{OH})$ radical is known to be generated by photochemical reactions in natural waters. As the most oxidative reactant among the active oxygen species, it plays an important role in the transformation and oxidation of a variety of organic and inorganic compounds, including priority pollutants. Thus, estimation of its formation rate is significant for understanding these processes; however, its accurate estimation during long-term laboratory irradiations (days to weeks) has been problematic. This paper examines different approaches for accurately determining $\cdot \mathrm{OH}$ radical formation rates in natural waters using either short-term (hours) or long-term irradiations. It also discusses possible pathways of $\cdot \mathrm{OH}$ formation in long-term irradiations in relation to hydrogen peroxide and iron concentrations. The merit of this study is not only methodological improvement, but it also provides better understanding of phototransformation pathways of dissolved organic matter (DOM). 


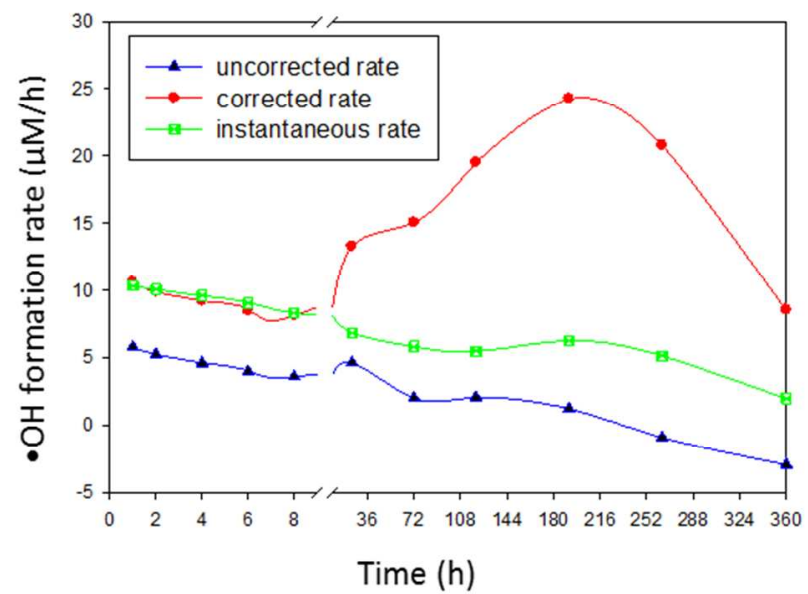

"Uncorrected rate, corrected rate and instantaneous rate of $\bullet \mathrm{OH}$ photoproduction in Dismal Swamp water." 


\title{
1 Estimating hydroxyl radical photochemical formation rates in natural
}

\section{2 waters during long-term laboratory irradiation experiments}

\author{
3 Luni Sun; Hongmei Chen; Hussain A. Abdulla; Kenneth Mopper*
}

\section{Abstract}

6 In this study it was observed that, during long-term irradiations ( $>2$ days) of natural waters, the 7 methods for measuring hydroxyl radical $(\bullet \mathrm{OH})$ formation rates based upon sequentially determined 8 cumulative concentrations of photoproducts from probes significantly underestimate actual $\bullet \mathrm{OH}$ 9 formation rates. Performing a correction using the photodegradation rates of the probe products improves the $\bullet \mathrm{OH}$ estimation for short term irradiations ( $<2$ days), but not long term irradiations. Only the 'instantaneous' formation rates, which were obtained by adding probes at each time point and irradiating the water sample (or sub-sample) for a short time ( $\leq 2 \mathrm{~h}$ ), were found appropriate for accurately estimating - $\mathrm{OH}$ photochemical formation rates during long-term laboratory irradiation experiments. Our results also showed that in iron- and dissolved organic matter (DOM)-rich water samples, $\bullet \mathrm{OH}$ appears to be mainly produced from the Fenton reaction initially, but subsequently from other sources possibly from DOM photoreactions. Pathways of $\bullet \mathrm{OH}$ formation in long-term irradiations in relation to $\mathrm{H}_{2} \mathrm{O}_{2}$ and iron concentrations are discussed.

\section{Introduction}

The hydroxyl radical $(\bullet \mathrm{OH})$ is the most oxidative reactant among the reactive oxygen species, it plays an important role in the transformation and oxidation of a variety of organic and inorganic compounds ${ }^{1,2}$. Photochemical reactions are the major sources of $\bullet \mathrm{OH}$ radical in natural waters. The photo-formation of - OH depends on its major sources in sunlit waters, which include DOM photoreactions, the photo-Fenton reaction, and nitrate and nitrite photolyses ${ }^{3}$. Nitrate and nitrite photolyses are often found to be important sources ${ }^{4}$, in rivers where their contributions are 1 89\% from nitrate and 2 70\% from nitrite, while in seawaters their contributions are 7 75\% from nitrate and 1 8\% from nitrite ${ }^{3}$. However, in iron-rich waters, the contribution of the photo-Fenton reaction (see below) can account for more than $70 \%$ the of total photochemical $\bullet \mathrm{OH}$ production ${ }^{5-7}$.

\footnotetext{
Department of Chemistry and Biochemistry, Old Dominion University, Norfolk, VA

* Corresponding author. Email: kmopper@odu.edu. Tel: 757-683-4094 Fax: 757-683-5310
} 
where $\mathrm{Fe}(\mathrm{II})$ and $\mathrm{Fe}(\mathrm{III})$ include the hydrated and DOM-complexed iron species. In seawater and high DOM freshwaters, DOM photoreactions appear to be the main source for $\bullet \mathrm{OH}^{2,8-12}$. Reactions involving

32 hydroquinolic and phenolic moieties within humic substances appear to be responsible, at least in part, for

$33 \cdot \mathrm{OH}$ photoproduction in these waters ${ }^{2,8}$.

34 In natural waters, photochemical formation rates of $\bullet \mathrm{OH}$ are determined indirectly using probes. The probe reactions can be split into two broad categories: 1) $\bullet \mathrm{OH}$ addition to probes, with $\bullet \mathrm{OH}$ either being added to the carbon atoms in probes such as 4-nitrophenol, nitrobenzene, benzene, benzoic acid, and terephthalate, or being added to the sulfoxide group in probes, e.g. dimethyl-sulfoxide; and 2) abstraction of a hydrogen atom on the probes such as methanol, formic acid, methane and butyl chloride ${ }^{8,13,14}$. Among these probes, benzene and benzoic acid have been commonly used. Typically, the probes are added initially to the samples and the cumulative concentrations of phenolic products are measured after irradiating for several minutes ${ }^{15}$ or hours ${ }^{3,10,16,17}$. These phenolic product compounds are non- or very weak absorbers of light in the solar irradiance spectrum and thus do not undergo direct photoreaction; however, in natural waters, their phototransformation/destruction may be promoted by the presence of DOM, possibly through electron or hydrogen atom transfer from reactive excited triplet states of $\mathrm{DOM}^{18 \text {, }}$ ${ }^{19}$, or reaction with reactive oxygen species, such as hydrogen peroxide ${ }^{20}$, and singlet oxygen ${ }^{21}$. Thus, during long-term irradiations, this loss may lead to significant underestimation of the cumulative concentrations of phenolic products. This underestimation is likely minor when only initial $\bullet \mathrm{OH}$ formation rates are taken into account ${ }^{17}$, but it may be significant for time-course studies of $\bullet \mathrm{OH}$ formation rates or its steady-state concentration, such as studies on the sources of $\bullet \mathrm{OH}$ which usually require several hours to adequately measure the generation of $\bullet \mathrm{OH}^{3,6,16}$. For example, in studies examining the photo-Fenton reaction in natural waters, the $\bullet \mathrm{OH}$ formation rate, and $\mathrm{H}_{2} \mathrm{O}_{2}$ and $\mathrm{Fe}$ (II) concentrations were measured hourly under different experimental conditions ${ }^{7}$. Moreover, DOM photochemical transformation studies usually run for hours to days ${ }^{22-24}$. Since DOM is an important source and sink of $\bullet \mathrm{OH}$ (as well as other reactive species), accurate estimation of $\bullet \mathrm{OH}$ can improve our understanding of DOM transformation pathways. Therefore, it is necessary to establish the stability of both the $\bullet \mathrm{OH}$ probe compound and the quantified product species with respect to direct and indirect

57 photolysis in natural waters ${ }^{25}$.

In this study, we estimated time-course $\bullet \mathrm{OH}$ formation rates in DOM-rich water (Great Dismal Swamp) and estuarine water by two approaches: 1) correcting for product loss and 2) obtaining nearinstantaneous formation rates. The corrected formation rates were obtained by adding the 
62 were obtained by adding probes at each time point and irradiating the sample for a short time $(\leq 2 \mathrm{~h})$.

63 Moreover, we discuss possible pathways of $\bullet \mathrm{OH}$ formation in iron- and DOM-rich samples during long64 term irradiations.

\section{Chemicals}

68 Phenol (purity grade $>99 \%$ ), sodium benzoate (99.5\%), benzene (HPLC grade), and desferrioxamine mesylate (DFOM) (92.5\%) were obtained from Sigma; salicylic acid (SA) (99\%) was obtained from Fisher; $\mathrm{H}_{2} \mathrm{O}_{2}(35 \%$ w/w) and methanol (HPLC grade) were obtained from Acros. Ultra-pure water (Milli-

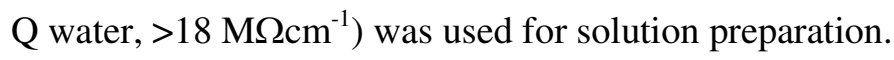

\section{Sample description}

74 Water samples were freshly obtained from the Great Dismal Swamp (near $36.7^{\circ} \mathrm{S}$ and $76.4^{\circ} \mathrm{W}$, salinity 0 ppm, pH 3.7) and Elizabeth River estuary (near $36.9^{\circ} \mathrm{S}$ and $76.3^{\circ} \mathrm{W}$, salinity $20 \mathrm{ppm}, \mathrm{pH} 7.5$ ) in spring 2013. Samples were filtered within 24 hours of collection through a pre-cleaned $0.1 \mu \mathrm{m}$ capsule filter (Polycap TC, Whatman). Dissolved organic carbon (DOC) and total dissolved nitrogen (TDN) were 54 ppm and 1.9 ppm for the Great Dismal Swamp sample, and 3 ppm and 0.9 ppm for the Elizabeth River estuarine sample.

\section{Irradiations}

All samples were placed into quartz tubes or flasks and kept oxygenated by periodic shaking in air. Irradiations were conducted using a solar simulator containing UVA340 bulbs (Q-Panel). The solar simulator is described elsewhere ${ }^{26}$. These lamps have a spectral output nearly identical to natural sunlight from $\sim 295$ to $\sim 360 \mathrm{~nm}$ (http://www.solarsys.biz/0103.shtml). In a comparison of the light output from the solar simulator to natural sunlight, the solar simulator provided $127 \%$ of the photobleaching occurring under winter mid-day sunlight at $36.89^{\circ} \mathrm{N}$ latitude ${ }^{27}$. Consequently, the $\cdot \mathrm{OH}$ production rates in this study are likely somewhat higher than in the environment. Dark controls were wrapped in foil and placed inside the solar simulator. All samples were irradiated at room temperature and at their natural concentrations and $\mathrm{pH}$ in order to approximately simulate surface conditions, and to avoid potential contamination.

\section{Determination of $\bullet \mathrm{OH}$ formation rate}

93 Probe compounds (sodium benzoate or benzene) were added to aliquots of the water sample to final 
vigorous stirring at room temperature. These samples were used to determine the effect of long-term, continuous irradiation of the $\bullet \mathrm{OH}$ probes. Other aliquots of the water sample were used for measuring instantaneous $\bullet \mathrm{OH}$ formation rates and parameters including DOC, TDN, DFe and $\mathrm{H}_{2} \mathrm{O}_{2}$ production. The instantaneous $\bullet \mathrm{OH}$ formation rates were determined by irradiating the latter aliquots without the probes present; subsamples were then removed at specific time points and irradiated for $\leq 2 \mathrm{~h}$ with the $\bullet \mathrm{OH}$ probes.

Benzoic acid reacts with $\bullet \mathrm{OH}$ to form SA and other products, while benzene reacts to form phenol and other products. The fraction of SA (or phenol) formed relative to the other $\bullet \mathrm{OH}$ photoproducts is constant ${ }^{10}$ thereby enabling the use of SA (or phenol) production to determine the total $\bullet \mathrm{OH}$ production, as described below. The SA and phenol photoproducts were measured using HPLC with fluorescence detection as described in detail elsewhere ${ }^{10,29}$; the excitation/emission wavelengths were $300 / 400 \mathrm{~nm}^{9}$ for SA and 260/310 nm for phenol $^{28}$, respectively. Cumulative SA and/or phenol concentrations were plotted vs. irradiation time. The observed photo-formation rates of SA and phenol $\left(\mathrm{R}_{\mathrm{ob}}\right)$ were determined from the tangent slopes at each time point of the curve using Matlab. $\mathrm{R}_{\mathrm{ob}}$ was used to evaluate the uncorrected $\bullet \mathrm{OH}$ photo-production rate, $\mathrm{R}_{\mathrm{unc}}$, which was calculated by the following equation:

$$
\mathrm{R}_{\mathrm{unc}}=\frac{\mathrm{R}_{\mathrm{ob}} \times \mathrm{F}}{\mathrm{Y}}
$$

111 where $\mathrm{Y}$ is the yield of photoproduct formed per probe molecule oxidized by $\bullet \mathrm{OH}$. Since the reaction

112 between probe and $\bullet \mathrm{OH}$ forms more than one product ${ }^{10,29}$, this value is always less than $100 \%$ (see

113 Results and Discussion). F is a calibration factor, which is related to the fraction of the $\bullet \mathrm{OH}$ flux that

114 reacts with the probe and accounts for competing $\mathrm{OH}$ scavengers in natural waters, such as DOM. F is

115 evaluated for each sample type by competition kinetics using a series of different probes concentrations as

116 described in detail by Zhou and Mopper ${ }^{30}$. For our experiments, F was 1.11 1.26, depending on the

117 probes and sample types.

\section{Determination of photodegradation rates of $\bullet \mathrm{OH}$ probe products}

120 Photodegradation rates of SA and phenol were obtained by irradiating $40 \mu \mathrm{M}$ SA and $180 \mu \mathrm{M}$ phenol 121 in the Dismal Swamp sample and measuring their concentrations over $24 \mathrm{~h}$. The concentrations of SA 122 and phenol chosen were close to the maximum cumulative concentrations formed in our irradiation 123 experiments. 
127

128

129

130

131

132

133

134

135

136

137

138

139

140

141

142

143

144

145

146

147

148

149

150

151

152

153

154

155

DOC and TDN were measured for all samples using high temperature $\left(720^{\circ} \mathrm{C}\right)$ catalytic combustion on a Shimadzu TOC-V-CPH carbon analyzer. DFe concentration and $\mathrm{H}_{2} \mathrm{O}_{2}$ production were measured for Dismal Swamp sample. DFe was measured using a Hitachi Z8100 polarized Zeeman flame atomic absorption spectrophotometer equipped with an iron hollow cathode lamp; and $\mathrm{H}_{2} \mathrm{O}_{2}$ production was measured by modified (p-hydroxyphenyl)-acetic acid dimerization method ${ }^{31}$.

\section{Results and Discussions}

\section{Calibration of $\mathbf{Y}_{\mathbf{p h}}$ value}

$\mathrm{Y}$ is the yield of photoproduct formed per probe molecule oxidized by $\bullet \mathrm{OH}$. Most $\mathrm{Y}$ values of SA ( $\left.\mathrm{Y}_{\mathrm{SA}}\right)$ from published radiolysis experiments are $17 \sim 18 \%{ }^{10,14,32}$ while the values of phenol $\left(\mathrm{Y}_{\mathrm{ph}}\right)$ range from $66 \%$ to $95 \%{ }^{14,33-35}$; the high $\mathrm{Y}_{\mathrm{ph}}$ of $95 \%$ was observed during nitrate photolysis ${ }^{35}$. Because of the wide range of published $\mathrm{Y}_{\mathrm{ph}}$ values, we did not select a $\mathrm{Y}_{\mathrm{ph}}$ value for our system from published data. Instead, we used the much less variable $\mathrm{Y}_{\mathrm{SA}}$ value $\left(17 \%{ }^{10}\right.$ ) to calibrate the $\mathrm{Y}_{\mathrm{ph}}$ value by using $\mathrm{H}_{2} \mathrm{O}_{2}$ photolysis as a pure $\bullet \mathrm{OH}$ source. Different concentrations of $\mathrm{H}_{2} \mathrm{O}_{2}$ were added to solutions containing sodium benzoate or benzene and irradiated for $1 \mathrm{~h}$. Assuming the degradation of SA and phenol is negligible in this short period, at the same concentrations of $\mathrm{H}_{2} \mathrm{O}_{2}$, the $\bullet \mathrm{OH}$ photoproduction rate $\mathrm{R}_{\text {unc }}$ should be the same for both probes, that is:

$$
\mathrm{R}_{\mathrm{unc}=} \frac{\mathrm{R}_{\mathrm{SA}} \times \mathrm{F}_{\mathrm{SA}}}{\mathrm{Y}_{\mathrm{SA}}}=\frac{\mathrm{R}_{\mathrm{ph}} \times \mathrm{F}_{\mathrm{ph}}}{\mathrm{Y}_{\mathrm{ph}}}
$$

but, since there are no other competing scavengers, $\mathrm{F}_{\mathrm{SA}}=\mathrm{F}_{\mathrm{ph}}=1$ :

$$
\mathrm{R}_{\mathrm{unc}}=\frac{\mathrm{R}_{\mathrm{SA}}}{\mathrm{Y}_{\mathrm{SA}}}=\frac{\mathrm{R}_{\mathrm{ph}}}{\mathrm{Y}_{\mathrm{ph}}}
$$

$\mathrm{Y}_{\mathrm{ph}}$ was then calculated as:

$$
\mathrm{Y}_{\mathrm{ph}}=\frac{\mathrm{Y}_{\mathrm{SA}} \times \mathrm{R}_{\mathrm{ph}}}{\mathrm{R}_{\mathrm{SA}}}
$$

In our experiments, $\mathrm{Y}_{\mathrm{ph}}$ value was calculated as $69.3 \pm 2.2 \%$, which was then used for all calculations.

$$
\text { This value is in agreement with most published values }{ }^{21-24} \text {. }
$$

\section{Corrections of $\bullet \mathrm{OH}$ formation rates}

53 Photodegradation was observed for both SA and phenol, and followed first order reaction kinetics. The photodegradation rate at each time point is $k[\mathrm{SA} \text { or phenol }]_{\mathrm{t}}$, where $k$ is the slope of the plot of $\mathrm{Ln}$ (concentration) vs. the irradiation time; it is $-0.0495 \mathrm{~h}^{-1}$ for SA and $-0.0459 \mathrm{~h}^{-1}$ for phenol (Fig. 1). 


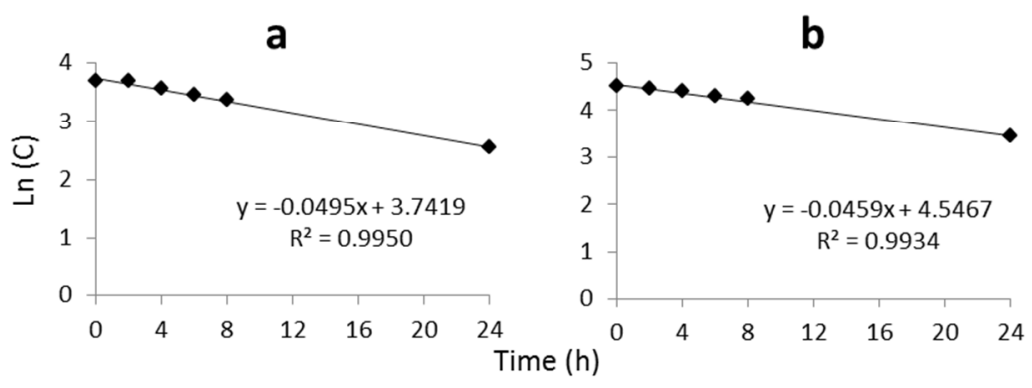

156

157

158

159

160

161

162

163

164

165

166

167

168

169

170

171

172

173

174

175

176

177

178

179

180

181

Fig. 1 SA (a) and phenol (b) photodegradation in the Dismal Swamp sample over a $24 \mathrm{~h}$ irradiation in a UV solar simulator. Subsamples for measuring SA and phenol degradation rates were taken at the same time as the $\bullet \mathrm{OH}$ measurements.

The corrected photoformation rate of SA or phenol is the observed SA (or phenol) formation rate $\left(\mathrm{R}_{\mathrm{ob}}\right)$ plus its degradation rate. Therefore, the $\bullet \mathrm{OH}$ formation rate $\left(\mathrm{R}_{\text {cor }}\right)$ was corrected and calculated by the following equation:

$\mathrm{R}_{\text {cor }}=\longrightarrow=\mathrm{R}_{\mathrm{unc}}+$

Uncorrected $\bullet \mathrm{OH}$ formation rate $\left(\mathrm{R}_{\mathrm{unc}}\right)$, corrected formation rate $\left(\mathrm{R}_{\mathrm{cor}}\right)$, and instantaneous formation rates $\left(\mathrm{R}_{\text {ins }}\right)$ at each time point during $15 \mathrm{~d}$ are shown in Fig. 2 and Fig. 3. $R_{\text {ins }}$ was assumed to be the true - $\mathrm{OH}$ formation rate; i.e., the degradation of SA or phenol is negligible for a one hour irradiation (Fig. 1). The negative $\mathrm{R}_{\mathrm{unc}}$ values at the longer irradiation times (Fig. 2 and Fig. 3 ) is probably due to the substantial photodegradation of the probe photoproducts upon long-term irradiation.

\section{Comparison of $\bullet \mathrm{OH}$ formation rates}

Between $2 \mathrm{~h}$ and $8 \mathrm{~h}, \mathrm{R}_{\mathrm{unc}}$ values were lower than $\mathrm{R}_{\mathrm{ins}}$ values (Table 1). The differences averaged $29 \%$ using benzoic acid and $16 \%$ using benzene as probes; thus $\mathrm{R}_{\mathrm{OH}}$ significantly underestimated $\bullet \mathrm{OH}$ formation. By performing corrections for probe product degradation, the agreement improved. The differences between $\mathrm{R}_{\text {cor }}$ and $\mathrm{R}_{\text {ins }}$ averaged $8 \%$ using benzoic acid and $4 \%$ using benzene as probes. However, for longer irradiation periods (more than $8 \mathrm{~h}$ ), neither $\mathrm{R}_{\mathrm{unc}}$ nor $\mathrm{R}_{\text {cor }}$ agreed well with $\mathrm{R}_{\mathrm{ins}}$, as differences were $>30 \%$. The reason for the large discrepancies might be that the added probes changed DOM photodegradation and $\mathrm{OH}$ production pathways, which only became significant after long-term irradiations containing the probe. Therefore, for long-term irradiations (e.g., $>\sim 1$ day) $\mathrm{R}_{\text {ins }}$ should be used to determine the $\mathrm{OH}$ production rate. There were no significant differences in $\mathrm{R}_{\text {ins }}$ between two different probes (paired t test, $\mathrm{P}=0.1066$ ) for up to 15 days of irradiation (Fig. 4). 
182

183

184

185

186

187

188

189

190

Table 1. Uncorrected $\bullet \mathrm{OH}$ formation rate $\left(\mathrm{R}_{\mathrm{unc}}\right)$, corrected formation rate $\left(\mathrm{R}_{\mathrm{cor}}\right)$, and instantaneous formation rates $\left(\mathrm{R}_{\mathrm{ins}}\right)$ during $8 \mathrm{~h}(\mathrm{n}=2)$

\begin{tabular}{ccccccc}
\hline \multirow{2}{*}{ Time (h) } & \multicolumn{5}{c}{$\cdot$ OH fomation rates $(\mu \mathrm{M} / \mathrm{h})$ by using } \\
& $\mathrm{R}_{\text {unc }}$ & $\mathrm{R}_{\text {cor }}$ & $\mathrm{R}_{\text {ins }}$ & $\mathrm{R}_{\text {unc }}$ & $\mathrm{R}_{\text {cor }}$ & $\mathrm{R}_{\text {ins }}$ \\
& $10.5 \pm 0.1$ & $11.0 \pm 0.1$ & $10.8 \pm 0.1$ & $10.3 \pm 0.5$ & $10.6 \pm 0.5$ & $10.7 \pm 0.1$ \\
1 & $9.0 \pm 0.1$ & $9.9 \pm 0.1$ & $10.1 \pm 0.4$ & $9.3 \pm 0.4$ & $9.9 \pm 0.5$ & $10.0 \pm 0.4$ \\
2 & $6.5 \pm 0.3$ & $8.3 \pm 0.3$ & $9.6 \pm 0.4$ & $8.0 \pm 0.1$ & $9.0 \pm 0.1$ & $9.6 \pm 0.5$ \\
4 & $5.6 \pm 0.2$ & $7.8 \pm 0.2$ & $9.0 \pm 0.3$ & $7.2 \pm 0.1$ & $8.6 \pm 0.1$ & $9.0 \pm 0.3$ \\
6 & $5.2 \pm 0.4$ & $8.0 \pm 0.4$ & $8.3 \pm 0.5$ & $6.6 \pm 0.6$ & $8.1 \pm 0.6$ & $8.3 \pm 0.5$ \\
8 & & & & & & \\
\hline
\end{tabular}

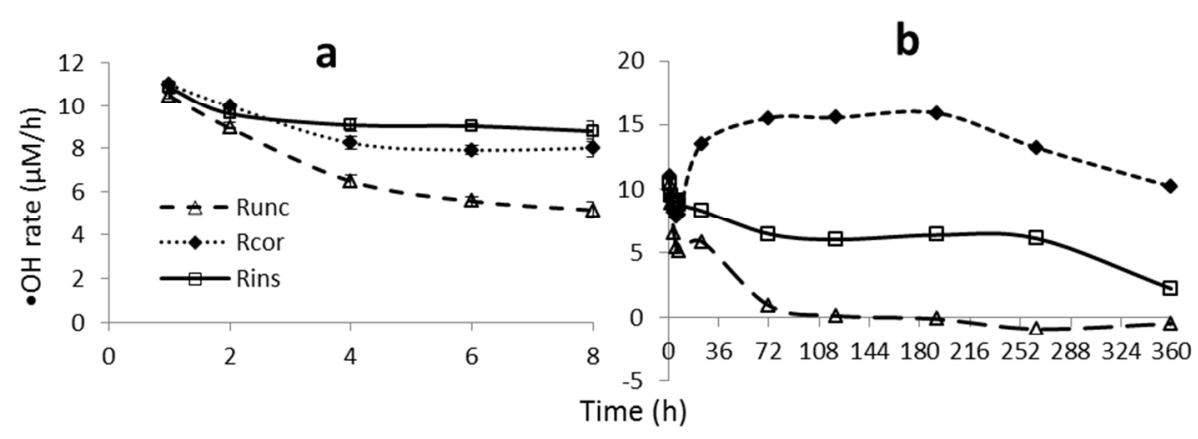

Fig. $2 R_{\text {unc }}, R_{\text {cor }}$ and $R_{\text {ins }}$ using benzoic acid as probe for $8 \mathrm{~h}(\mathrm{a})$ and 15 day (b) irradiations of Dismal Swamp water. Error bars are within the data points unless otherwise indicated.

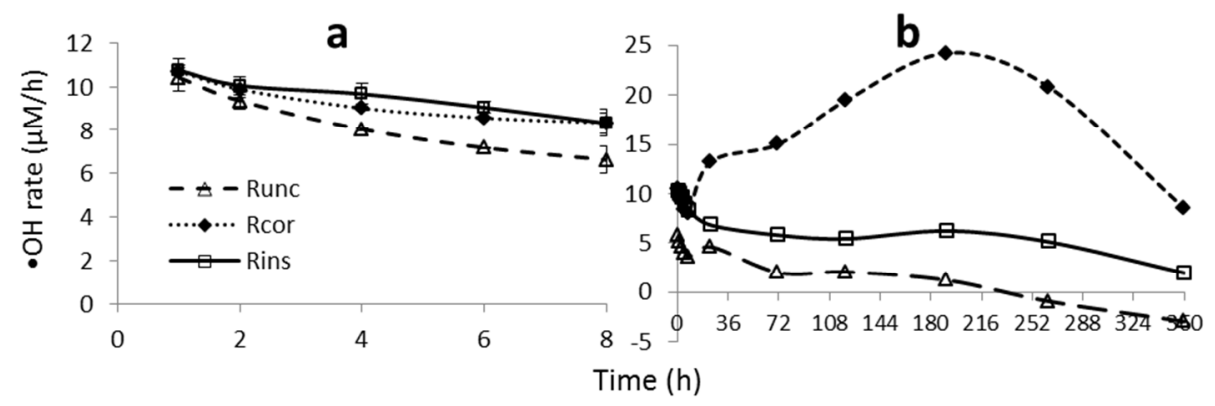

Fig. 3. $R_{\text {unc }}, R_{\text {cor }}$ and $R_{\text {ins }}$ using benzene as probe for $8 \mathrm{~h}$ (a) and 15 day (b) irradiations of Dismal Swamp water. Error bars are within the data points unless otherwise indicated. 


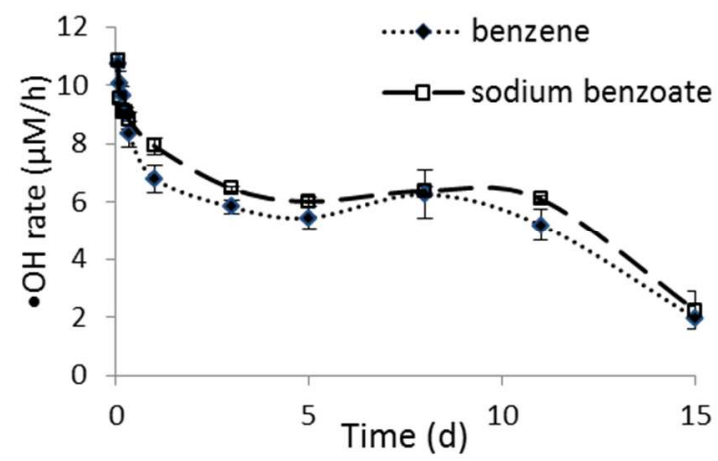

Fig.4. Comparison of $\mathrm{R}_{\mathrm{ins}}$ between two probes for a 15 day irradiation of Dismal Swamp water. Error bars are within the data points unless otherwise indicated.

Measurements were also conducted in a low DOC (3 ppm) sample from the Elizabeth River (salinity of 20). Only benzene was used as the $\bullet \mathrm{OH}$ probe because it has higher $\mathrm{Y}$ and, thus a somewhat better selectivity than benzoic acid ${ }^{36}$; and its corresponding photoproduct phenol has higher fluorescent intensity than SA. The photodegradation rate of phenol in the Elizabeth River sample was $0.00443 \mathrm{~h}^{-1}$, which is only $1 / 10$ of that for the Dismal Swamp water sample. $\bullet \mathrm{OH}$ formation rates were also low in the Elizabeth River sample $(<40 \mathrm{nM} / \mathrm{h})$. However, this is not only due to low DOM, but also due to competing natural $\cdot \mathrm{OH}$ scavengers including $\mathrm{CO}_{3}{ }^{2-}$ and $\mathrm{Br}^{-}$in saline water ${ }^{12,37}$. The t test showed no significant differences between $R_{\text {unc }}, R_{\text {cor }}$ and $R_{\text {ins }}$ during $6 \mathrm{~h}$ of irradiation ( $P>0.17$ ) (Fig. 5. a): thus, use of a correction or instantaneous rate was not necessary. However, significant differences were observed for irradiations > $\sim 24 \mathrm{~h}$ (Fig. 5. b); thus the measurement of $\mathrm{R}_{\text {ins }}$ also appears to be necessary for long-term irradiations, even for this relatively low DOC sample.

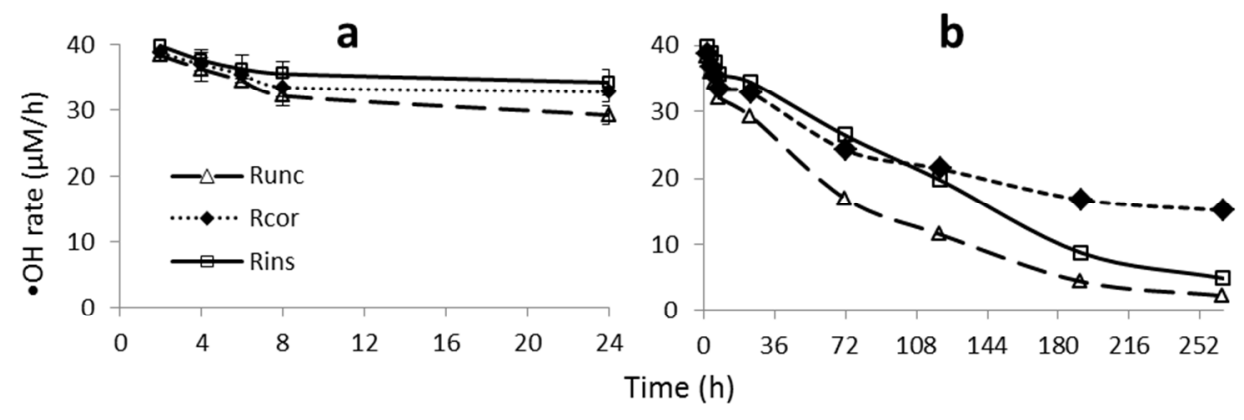

Fig. 5. $\mathrm{R}_{\text {unc }}, \mathrm{R}_{\text {cor }}$ and $\mathrm{R}_{\text {ins }}$ for $24 \mathrm{~h}$ and 11 day irradiations of Elizabeth River water. Error bars are within the data points unless otherwise indicated.

\section{Possible $\bullet$ OH formation pathways in Dismal Swamp water}


$211 \mathrm{R}_{\text {ins }}$ values were positive through 15 days of continuous irradiation, and ranged from $\sim 10.5 \mu \mathrm{M} / \mathrm{h}$ on 212 day 1 to $\sim 2 \mu \mathrm{M} / \mathrm{h}$ on day 15 (Fig. 4). After day 1 , the rate decreased until a plateau at $\sim 6 \mu \mathrm{M} / \mathrm{h}$ was 213 reached (from $\sim$ day 3 to day 12 ), after which it dropped to $\sim 2 \mu \mathrm{M} / \mathrm{h}$ on day 15 . During the irradiation, 214 DFe decreased from nearly $20 \mu \mathrm{M}$ to $3 \mu \mathrm{M}$ (Fig. 6a), and photochemically-induced flocculation was 215 observed after day 4. The photoproduction of $\mathrm{H}_{2} \mathrm{O}_{2}$ varied widely over the irradiation (Fig. 6c.d). $\mathrm{H}_{2} \mathrm{O}_{2}$ 216 showed strong initial production, but fell to zero between day 2 and day 4, and then was produced again 217 after day 4 upon the onset of flocculation. We hypothesize that the photo-Fenton reaction was the main 218 source of the $\cdot \mathrm{OH}$ initially, on the basis of high $\mathrm{DFe}$ and high $\mathrm{H}_{2} \mathrm{O}_{2}$ photoproduction from DOM during 219 the first day. Nitrate photolysis was likely a negligible source of $\bullet \mathrm{OH}$ as the maximum $\bullet \mathrm{OH}$ production 220 from nitrate was only $\sim 2.1 \times 10^{-3} \mu \mathrm{M} / \mathrm{h}$, based on a dissolved nitrogen concentration and assuming all 221 dissolved nitrogen was nitrate and assuming an $\bullet \mathrm{OH}$ photo-production rate from nitrate of $\sim 1.1 \times 10^{-3} \mu \mathrm{M}$ $222 \cdot \mathrm{OH} / \mathrm{h}$ per $\mu \mathrm{M}$ nitrate ${ }^{12}{ }^{37}$. To test for the effect of iron (i.e., the photo-Fenton reaction), an aliquot of 223 Dismal Swamp sample was irradiated with $100 \mu \mathrm{M}$ DFOM, which effectively binds all DFe into a photochemically unreactive complex ${ }^{6}$. The DFOM addition reduced the $\bullet \mathrm{OH}$ formation rate by about $90 \%$ during an $8 \mathrm{~h}$ irradiation, thus confirming the initial importance of Fenton chemistry in $\bullet \mathrm{OH}$ photoproduction in the Dismal Swamp sample. Between day 4 to day $7, \mathrm{H}_{2} \mathrm{O}_{2}$ was again being photoproduced (Fig. 6c, d), but a sharp decrease in DFe was also observed during this period, which is likely decreased the importance of Fenton chemistry relative to $\mathrm{OH}$ photoproduction from other sources, in particular DOM photoreactions ${ }^{23}$. The reasons for the reappearance of $\mathrm{H}_{2} \mathrm{O}_{2}$ after day 4 are not known, but may be related to major photochemically-induced changes in DOM composition and structure ${ }^{38}$ and to the initialization of DOM photoflocculation after day $4^{23,39}$. This is supported by the inverse relation $\left(\mathrm{R}^{2}=0.97\right)$ between the DOC-normalized $\mathrm{OH}$ production rate and the DOC-normalized DFe concentration, particularly after day 4 (Fig. 6b). To our knowledge, this behavior of $\mathrm{H}_{2} \mathrm{O}_{2}$ photoproduction has not been previously observed and, thus, warrants further study. After day 10, as most DOM had been degraded or mineralized, $\bullet \mathrm{OH}$ formation decreased again.

It needs to be pointed out that, in addition to trapping the free $\bullet \mathrm{OH}$, these probes (as well as most other commonly used $\bullet \mathrm{OH}$ probes) also react with other highly reactive hydroxylating species ${ }^{8,40-42}:$ e.g., excited quinones triplets photochemically produce a species capable of hydroxylation, even though these species exhibit reactivities about one an order of magnitude lower than the free $\bullet \mathrm{OH}^{40}$. As quinone structures were observed in the Dismal Swamp DOM by FTIR (unpublished data), it is likely that these 241 hydroxylating species contributed to the formation of hydroxylated compounds from the added probes. 242 Moreover, during the photo-Fenton reaction, the highly reactive and oxidizing ferryl ion, Fe(IV), can be 243 formed, although at relatively low rates ${ }^{34,43}$. This species is capable not only of abstraction of a hydrogen 
atom, even from methane ${ }^{44}$, but also of aromatic and benzylic hydroxylation, e.g. conversion of benzene to phenol ${ }^{45,46}$. Although the ferryl ion is less oxidizing than the hydroxyl radical ${ }^{47}$, we cannot reject its possible minor contribution to probe product formation in our iron rich system. Thus, in this study, all reported $\bullet \mathrm{OH}$ production rates include both free $\bullet \mathrm{OH}$ and any highly reactive species capable of hydroxylation the probe molecules. However, even if part of the probe product signal is due these other reactive species, they (in addition to $\bullet \mathrm{OH}$ ) may have played role in the transformation of DOM, as DOC decreased about $75 \%$ after 15 days irradiation, in agreement with Helms et al. ${ }^{39}$. Details of phototransformation pathways of DOM will be further discussed in a future study.
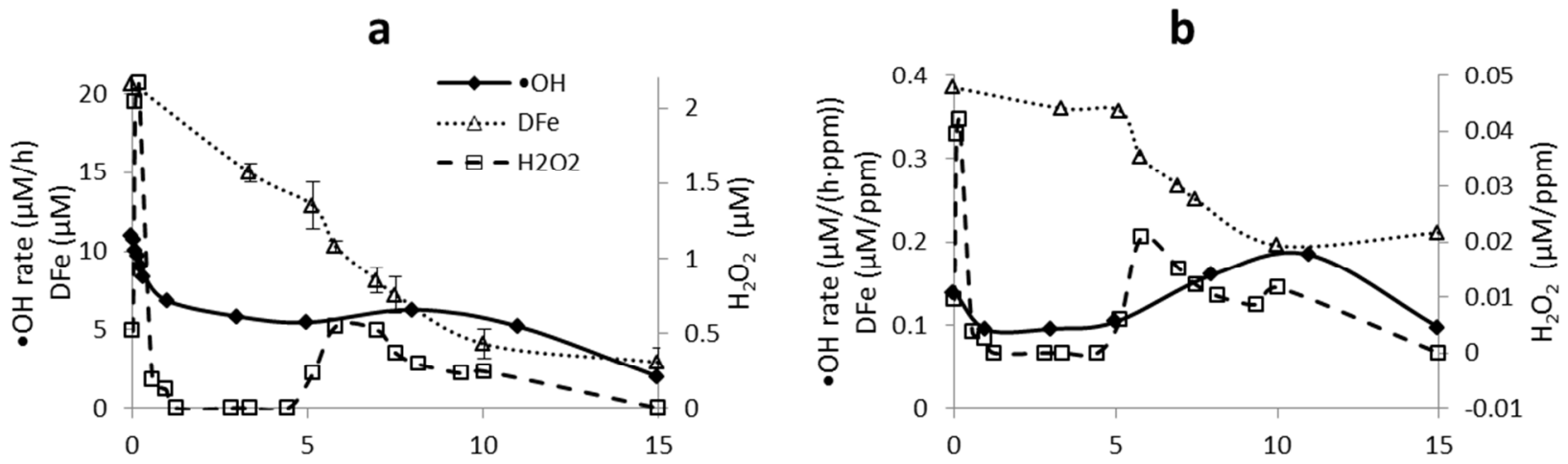

C

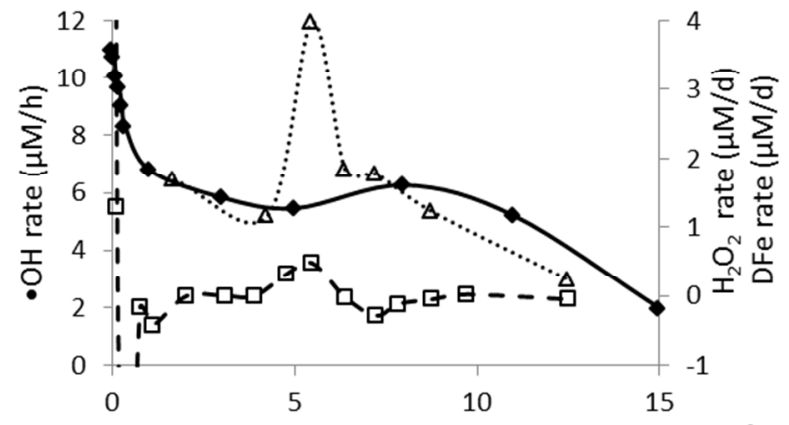

d

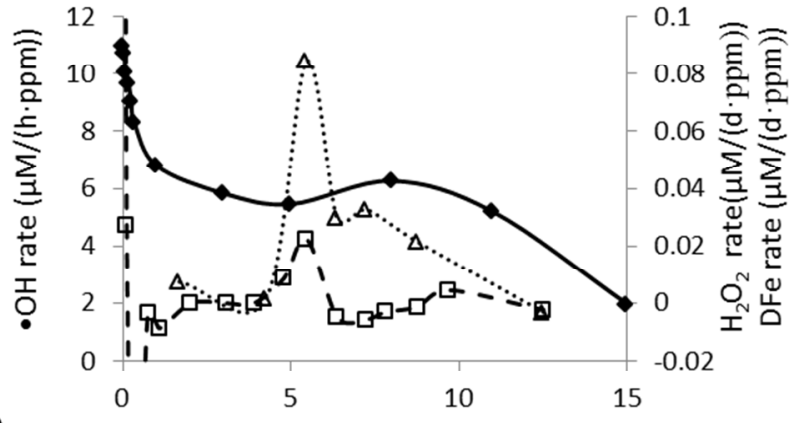

Time (d)

253 Fig.6. (a) $\bullet \mathrm{OH}$ formation rate, DFe and $\mathrm{H}_{2} \mathrm{O}_{2}$ concentration; (b) $\bullet \mathrm{OH}$ formation rate, $\mathrm{DFe}$ and $\mathrm{H}_{2} \mathrm{O}_{2}$ concentration

254 normalized to DOC; (c) $\bullet \mathrm{OH}$ formation rate, DFe loss rate and $\mathrm{H}_{2} \mathrm{O}_{2}$ formation rate; (d) $\bullet \mathrm{OH}$ formation rate, $\mathrm{DFe}$

255 loss rate, and $\mathrm{H}_{2} \mathrm{O}_{2}$ formation rate normalized to DOC during irradiation. $\bullet \mathrm{OH}(\bullet), \mathrm{H}_{2} \mathrm{O}_{2}(\square)$, and DFe $(\Delta)$.

256 Equivalent time points for iron and $\mathrm{H}_{2} \mathrm{O}_{2}$ were calibrated based on measured DOC in photodegraded subsamples

257 relative to the original sample (DOC as \%). 
In both DOM-rich and poor natural waters examined in this study, the methods for measuring $\bullet \mathrm{OH}$ formation rates by obtaining sequential cumulative concentrations of photoproducts from probes substantially underestimated the actual $\bullet \mathrm{OH}$ formation rate during long-term irradiations. Therefore, it is recommended that instantaneous formation rates be used to estimate $\bullet \mathrm{OH}$ photochemical formation rates during long-term irradiation experiments, regardless of the probe used. For short-term irradiations of natural waters, it is recommended that photodegradation rates of corresponding probe photoproducts be determined in order to correct the $\mathrm{OH}$ production rate. Our results also showed that, in the iron- and DOM-rich sample, $\bullet \mathrm{OH}$ is likely produced mainly from the Fenton and photo-Fenton reactions initially, but after that, $\bullet \mathrm{OH}$ appears to be produced mainly by other pathways, in particular DOM photoreactions, the mechanisms of which need to be further studied.

\section{Acknowledgments}

This research was supported by NSF grant OCE0850635 (to KM) awarded through the Chemical Oceanography Program.

\section{References}

1. G. V. Buxton, C. L. Greenstock, W. P. Helman and A. B. Ross, Phys. Chem. Ref. Data, 1988, 17, 513-886.

2. P. P. Vaughan and N. V. Blough, Environmental Science \& Technology, 1998, 32, 2947-2953.

3. K. G. Mostofa, C.-q. Liu, H. Sakugawa, D. Vione, D. Minakata, M. Saquib and M. A. Mottaleb, in Photobiogeochemistry of Organic Matter, eds. K. M. G. Mostofa, T. Yoshioka, A. Mottaleb and D. Vione, Springer Berlin Heidelberg, Editon edn., 2013, pp. 209-272.

4. J. Hoigné, C. Faust Bruce, R. Haag Werner, E. Scully Frank and G. Zepp Richard, in Aquatic Humic Substances, American Chemical Society, Editon edn., 1988, vol. 219, pp. 363-381.

5. B. A. Southworth and B. M. Voelker, Environmental Science \& Technology, 2003, 37, 1130-1136.

6. E. White, P. Vaughan and R. Zepp, Aquatic Sciences, 2003, 65, 402-414.

7. E. M. White, Ohio State University, 2000.

8. S. E. Page, W. A. Arnold and K. McNeill, Environmental Science \& Technology, 2011, 45, 28182825.

9. J. Qian, K. Mopper and D. J. Kieber, Deep Sea Research Part I: Oceanographic Research Papers, 2001, 48, 741-759.

10. X. Zhou and K. Mopper, Marine Chemistry, 1990, 30, 71-88.

11. J. Qian, Washington State University, 1996.

12. K. Mopper and X. Zhou, Science, 1990, 250, 661-664.

13. S. E. Page, W. A. Arnold and K. McNeill, Journal of Environmental Monitoring, 2010, 12, 16581665.

14. C. Anastasio and K. G. McGregor, Atmospheric Environment, 2001, 35, 1079-1089. 
15. T. Arakaki and B. C. Faust, Journal of Geophysical Research: Atmospheres (1984-2012), 1998, 103, 3487-3504.

16. N. Nakatani, M. Ueda, H. Shindo, K. Takeda and H. Sakugawa, Analytical Sciences, 2007, 23, 1137-1142.

17. F. al Housari, D. Vione, S. Chiron and S. Barbati, Photochemical \& Photobiological Sciences, 2010, 9, 78-86.

18. S. Canonica, U. Jans, K. Stemmler and J. Hoigne, Environmental science \& technology, 1995, 29, 1822-1831.

19. K. S. Golanoski, S. Fang, R. Del Vecchio and N. V. Blough, Environmental Science \& Technology, 2012, 46, 3912-3920.

20. J. Beltran-Heredia, J. Torregrosa, J. R. Dominguez and J. A. Peres, Chemosphere, 2001, 42, 351359.

21. F. Wilkinson, W. P. Helman and A. B. Ross, Journal of Physical and Chemical Reference Data, 1995, 24, 663.

22. M. A. Moran and R. G. Zepp, Limnology and Oceanography, 1997, 42, 1307-1316.

23. J. R. Helms, J. Mao, K. Schmidt-Rohr, H. Abdulla and K. Mopper, Geochimica et Cosmochimica Acta, 2013, 121, 398-413.

24. K. Mopper and D. J. Kieber, The effects of UV radiation in the marine environment, 2000, 10, 101-129.

25. J. Burns, W. Cooper, J. Ferry, D. W. King, B. DiMento, K. McNeill, C. Miller, W. Miller, B. Peake, S. Rusak, A. Rose and T. D. Waite, Aquat. Sci., 2012, 74, 683-734.

26. E. Minor, B. Dalzell, A. Stubbins and K. Mopper, Aquat. Sci., 2007, 69, 440-455.

27. J. R. Helms, A. Stubbins, J. D. Ritchie, E. C. Minor, D. J. Kieber and K. Mopper, Limnology and Oceanography, 2008, 53, 955.

28. K. Takeda, H. Takedoi, S. Yamaji, K. Ohta and H. Sakugawa, Analytical sciences, 2004, 20, 153158.

29. S. P. Mezyk, T. J. Neubauer, W. J. Cooper and J. R. Peller, The Journal of Physical Chemistry A, 2007, 111, 9019-9024.

30. K. Mopper, X. Zhou, R. J. Kieber, D. J. Kieber, R. J. Sikorski and R. D. Jones, Nature, 1991, 353, 6062.

31. W. L. Miller and D. R. Kester, Analytical Chemistry, 1988, 60, 2711-2715.

32. R. Matthews and D. Sangster, The Journal of Physical Chemistry, 1965, 69, 1938-1946.

33. I. Loeff and G. Stein, Journal of the Chemical Society (Resumed), 1963, 2623-2633.

34. I. Balakrishnan and M. P. Reddy, The Journal of Physical Chemistry, 1970, 74, 850-855.

35. C. Minero, S. Chiron, G. Falletti, V. Maurino, E. Pelizzetti, R. Ajassa, M. Carlotti and D. Vione, Aquat. Sci., 2007, 69, 71-85.

36. D. Vione, M. Ponzo, D. Bagnus, V. Maurino, C. Minero and M. Carlotti, Environ Chem Lett, 2010, 8, 95-100.

37. R. G. Zepp, J. Hoigne and H. Bader, Environmental Science \& Technology, 1987, 21, 443-450.

38. M. Gonsior, B. M. Peake, W. T. Cooper, D. Podgorski, J. D'Andrilli and W. J. Cooper, Environmental science \& technology, 2009, 43, 698-703.

39. J. R. Helms, A. Stubbins, E. M. Perdue, N. W. Green, H. Chen and K. Mopper, Marine Chemistry, 2013, 155, 81-91.

40. A. Pochon, P. P. Vaughan, D. Gan, P. Vath, N. V. Blough and D. E. Falvey, The Journal of Physical Chemistry A, 2002, 106, 2889-2894.

41. V. Maurino, D. Borghesi, D. Vione and C. Minero, Photochemical \& Photobiological Sciences, 2008, 7, 321-327. 
344 42. W. J. Cooper, R. G. Zika, R. G. Petasne and A. M. Fischer, Adv. Chem. Ser, 1989, 219, 333-362.

345 43. S. H. Bossmann, E. Oliveros, S. Göb, S. Siegwart, E. P. Dahlen, L. Payawan, M. Straub, M. Wörner and A. M. Braun, The Journal of Physical Chemistry A, 1998, 102, 5542-5550.

347

348

349

350

351

44. K. Yoshizawa, Y. Shiota and T. Yamabe, Journal of the American Chemical Society, 1998, 120, 564-572.

45. A. Bassan, M. R. A. Blomberg and P. E. M. Siegbahn, Chemistry - A European Journal, 2003, 9, 4055-4067.

46. J. Baxendale and J. Magee, Discussions of the Faraday Society, 1953, 14, 160-169.

47. W. Koppenol and J. F. Liebman, The Journal of Physical Chemistry, 1984, 88, 99-101. 